\title{
A PROSPECTIVE STUDY OF SAFETY PROFILE AND EFFICACY OF THREE DOSES OF INTRAVITREAL BEVACIZUMAB IN DIABETIC MACULAR EDEMA
}

\author{
Nasrin $Y^{1}$, Sharma Ajay ${ }^{2}$, Sharmila Yalakala ${ }^{3}$ \\ ${ }^{1}$ Head of Conea and general Ophthalmology, Sankar Foundation Eye Institute, Visakhapatnam, Andhra Pradesh, India \\ ${ }^{2}$ Department of Vitreo Retinal Services, Sankar Foundation Eye Institute, Visakhapatnam, Andhra Pradesh, India \\ ${ }^{3}$ DNB student, Sankar Foundation Eye Institute, Visakhapatnam, Andhra Pradesh, India
}

\begin{abstract}
Introduction: Current study aimed to evaluate efficacy of intravitreal Bevacizumab in Diabetic macular edema, and to identify their ocular and systemic complications if any.

Methods: All patients with resistant, center involving macular edema due to diabetes, retinal vein occlusion and age related macular degeneration were recruited. Complete baseline ocular examination performed at presentation. All patients were treated by 3 injection of intravitreal bevacizumab with 1 month interval. Outcome was measured in terms of variation in central macular thickness (CMT) and also best corrected visual acuity (BCVA) at 6 months.
\end{abstract}

Result: Total of 82 eyes of 68 patients completed whole duration of study with mean age of $59 \pm$ 6.72 years. The mean duration of diabetes was $11.68 \pm 7.2$ years. There was significant difference $(p<0.01)$ observed in the mean BCVA (log MAR) units at baseline and after 6 months i.e. $0.64 \pm 0.28$ vs $0.23 \pm 0.27$ (Snellen's equivalent 6/36). The mean Central macular thickness was significantly reduced at 1st, 3rd and 6th month $(P<0.01)$. Spearman's Correlation analysis between CMT and Log MAR units showed the correlation coefficient of $0.54,0.07$, and 0.75 were seen at Pre intervention, at 3 Months, and at 6 Months with significant difference $(P<0.01)$. The subconjunctival haemorrhage post injection day 1 seen in 10.9\%-12.1\% cases, and raised intraocular pressure (IOP) at post injection day 1 in 2.4\%-3.6\% cases. But, no complications seen at $3^{\text {rd }}$ and $6^{\text {th }}$ month followups. In persistent macular edema, significant resolution $(p=0.01)$ of $C M T$ was seen $(545.91 \pm 111.97 \mu m$ vs. $341.08 \pm 122.75 \mu \mathrm{m}$ baseline/6month) without significant ( $p=0.09)$ improvement in visual acuity $(0.85 \pm 0.28 \mathrm{vs}$. $0.34 \pm 0.23)$. Whereas, in refractory macular edema, no significant resolution ( $p>0.05$ ) of CMT was seen (482.53 $\pm 136.98 \mu \mathrm{m}$ vs. $407 \pm 169.64 \mu \mathrm{m}$ baseline/6month) without significant ( $p>0.05)$ improvement in visual acuity $(0.53 \pm 0.24 v s .0 .38 \pm 0.30)$. $69.5 \%$ cases improved $\geq 2$ Snellen lines at 3 months and $78 \%$ cases improved $\geq 2$ Snellen lines at 6 months. There were reduced macular edema seen in $69.5 \%$ cases, persistent macular edema in $12.1 \%$, refractory macular edema in $7.3 \%$ cases, and recurrence of macular edema in $10.9 \%$ cases. No other ocular and systemic complications were observed during follow-up.

Conclusion: Intravitreal bevacizumab is effective in treatment of diabetic macular edema but therapeutic effect is temporary and repeat treatment is needed. It does not show any potential drug related ocular and systemic side effects, hence it is safe and economical therapeutic agent.

\footnotetext{
Keywords: Diabetic Macular Edema, Proliferative Diabetic Retinopathy, Best Corrected Visual Acuity, Intravitreal Bevacizumab.

Cite This Article: Y, Nasrin; AJAY, Sharma; YALAKALA, Sharmila. A Prospective Study of Safety Profile and Efficacy of three doses of Intravitreal Bevacizumab in Diabetic Macular Edema. International Journal of Retina, [S.I.], v. 4, n. 2, p. 127, sep. 2021. ISSN 2614-8536. Available at: <https://www.ijretina.com/index.php/ijretina/article/view/171>.doi: https://doi.org/10.35479/ijretina.2021.v ol004.iss002.171.
} 
Correspondence to:

Sharma Ajay,

Department of Vitreo Retinal Services,

Sankar Foundation Eye Institute,

Visakhapatnam, Andhra Pradesh, India,

research@sankarfoundation.org

\section{INTRODUCTION}

Diabetes mellitus (DM) is a metabolic disease known since ancient times, characterized by hyperglycemia with its severe variations, secondary to the decrease of endogenous insulin secretion, action or both. ${ }^{1}$ The diabetic population in India is thought to be estimated as 69.9 million by 2025, and 80 million by $2030 .{ }^{2}$ The global prevalence of impaired glucose tolerance is estimated to be $7.5 \%$ (374 million) in 2019 and projected to reach $8.0 \%$ (454 million) by 2030 and $8.6 \%$ (548 million) by $2045 .^{3}$
The global prevalence of Diabetic retinopathy (DR) and diabetic macular edema (DME) were $27.0 \%$ for any DR comprising of 25.2\% NPDR, $1.4 \%$ PDR and 4.6\% DME during 2015 to $2019 .{ }^{4}$ Based on a study during a period of 10 years the development of DME occurred in $20.1 \%$ of patients with type 1 diabetes. ${ }^{5-}$ ${ }^{8}$ Diabetic retinopathy studies done in southern India showed that the range of prevalence of DR to be $12.2 \%$ to $18.03 \%$, in the DM population. The population above 50 years affected by DR was 16.6 \% to $20.9 \%{ }^{9}$

The Wisconsin Epidemiologic Study of Diabetic Retinopathy (WESDR) found the 14- year incidence of diabetic macular edema (DME) in type I DM to be $26 \% .^{5}$ Prevalence of DME is more in NPDR and increases with its severity. ${ }^{10} \mathrm{DME}$ can be diagnosed clinically as well as on OCT and fundus fluorescein angiography (FFA). ${ }^{11}$

Sustained-release corticosteroids developed to reduce the need for frequent intraocular injections in the treatment of DME. Fluocinolone acetonide implant is a non-biodegradable implant containing $0.59 \mathrm{mg}$ of the drug which releases drug for 2 years. A next-generation fluocinolone acetonide insert, Iluvien, developed as a non-biodegradable, sustained-release device containing $0.19 \mathrm{mg}$ drug, has been approved by the US FDA for the treatment of DME in patients who have not experienced a rise in IOP with steroids. ${ }^{12}$ Disadvantages of steroids are because of their side effects and occur in a dosedependent pattern. ${ }^{13}$ This increases the need for additional drugs, which controls the IOP. ${ }^{14}$

Intravitreal non-steroidal anti-inflammatory drugs (NSAIDs) have shown to reduce macular edema by inhibiting PG synthesis. Intravitreal diclofenac could possibly be as effective as steroid therapy, with added advantage of avoiding the related adverse effects such as IOP elevation. ${ }^{15}$

An intravitreal drug MP0112, a designated Ankyrin repeat protein selectively binds VEGF-A isoforms. Significant reductions in CMT and improvement in BCVA were noted, with the effects showing dosedependency. Furthermore, aqueous levels of MP0112 remained detectable after 12 weeks, suggesting a relatively long half-life of this drug. More RCT's are required to evaluate the efficacy of this drug. ${ }^{16}$

Another developed drug is PF-04523655 (PF), an siRNA that inhibits the RTP801 gene which is responsible for the production of hypoxia-inducible factor which, in turn, regulates VEGF production. The dose-ranging evaluation of intravitreal PF04523655 for diabetic macular edema trail resulted in greater BCVA improvements, although CMT reduction was only half as good as that seen with laser. A newly developed local treatment option for DME is subtenon injection of interferon- $\alpha$ (IFN $\alpha$ ). It acts as an inhibitor of VEGF and other cytokines and enhances the BRB. ${ }^{17}$ More studies are required to evaluate their efficacy.

For many years, laser was the only treatment option available for DME, but since 2011, other options started becoming available. Studies carried out to compare the effects of intravitreal anti-VEGF's and MLP in DME, which proves better outcome in anti- VEGF arm but with the need of monthly injections at least for first 3 months. ${ }^{18}$ 
Other agents such as intravitreal corticosteroids (CS) like Triamcinolone acetonide (TA), sustained-release implants like dexamethasone and Fluocinolone acetonide implants. These drugs eliminate the need for monthly injections but at the cost of various adverse effects like raised intraocular pressure (IOP) and early cataractous changes. Bevacizumab (BCZ) is a recombinant humanized monoclonal antibody with a molecular mass of $149 \mathrm{kDa}$ that effectively binds and inhibits all the isoforms of VEGF. ${ }^{19}$ Although BCZ has been approved for the treatment of metastatic malignancies such as colon cancer ${ }^{20}$ and ovarian cancer by the US $\mathrm{FDA}_{1}{ }^{21}$ it is being widely used off-label for the treatment of DME worldwide since 2005. The half-life of bevacuzumab in aqueous humor after intravitreal delivery of 1.5 mg was 9.82 days. Bevacizumab concentration peaked on post-injection day 1 , with a mean concentration of $33.3 \mu \mathrm{g} / \mathrm{ml}$ and dropped to less than $1 \mu \mathrm{g} / \mathrm{ml}$ at day 51.22

As to treatment for the recurrence of $\mathrm{ME}$, previous studies have shown that repeated injections with Intravitreal Bevacizumab are required to maintain good visual acuity. ${ }^{23,24}$ However, the best method (i.e. IVB, MLP, or combined therapy), criteria, and timing for retreatment are still unknown.

Hence, the present study was carried out to identify the safety and efficacy of bevacizumab in diabetic macular edema. Efficacy was assessed anatomically by CMT using OCT, functionally by BCVA. Safety was assessed by complication rate (ocular complications like subconjunctival haemorrhage, retinal breaks, retinal detachment, vitreous haemorrhage, glaucoma, cataract and systemic complications) after intravitreal bevacizumab.

Primary outcome of the study is to assess the mean resolution of central macular thickness by OCT after intravitreal bevacizumab, to calculate the improvement of BCVA and to evaluate ocular and systemic complications after intravitreal bevacizumab.

\section{METHOD}

A hospital based prospective interventional study conducted at a tertiary eye care institute Sankar Foundation Eye Hospital, Visakhapatnam.

Totally, 82 eyes of 68 patients with Diabetic macular edema those who are undergoing Intravitreal Avastin ${ }^{\circledR}$ injections for DME were included during July 2018 to December 2019 (1.5 years). Avastin ${ }^{\circledR}$ (Bevacizumab)[F.Hoffmann-La Roche Ltd, Grenzacherstrasse 124, CH-4070 Basel, Switzerland].

\section{Inclusion criteria:}

-Patients with presence of clinically significant macular edema in both PDR and NPDR with no prior treatment.

-Patients of either gender and with any type, duration, level of control and severity of diabetes mellitus.

- Central retinal thickness on OCT $>250 \mu$ or presence of cystic spaces.

-BCVA pre-treatment $\leq 6 / 12$.

\section{Exclusion criteria:}

-Macular edema secondary to causes other than DR.

-Vision loss secondary to cause other than DME.

-DME previously treated with intravitreal triamcinolone and/or other anti VEGF.

- Laser treatment done within previous 3 months.

- Corneal diseases, inflammatory eye diseases, optic neuropathy and age-related macular degeneration.

-Any ocular surgery within previous 6 months.

- Uncontrolled hypertension with thromboembolic events.

Intravitreal injection of bevacizumab: Procedure was performed in operation theatre. Topical anesthesia xylocaine was given after cleaning the ocular surface with povidone iodine $5 \%$ and using a sterile drape. Patients then receive intravitreal injection of $0.05 \mathrm{ml}$ volume containing $1.25 \mathrm{mg}$ of Avastin using a sharp 27- or 30-gauge needle at 3.5 $\mathrm{mm}$ posterior to limbus in pseudophakic eye and 4 $\mathrm{mm}$ posterior to limbus in phakic eyes. After injection antibiotic eye drops was applied 4 times a day for 1 week. All the patients was treated by 3 injections of Intravitreal bevacizumab with 1-month interval for each injection. 
All patients were examined on post op day 1 of each injection. The visual acuity was evaluated monthly, macular oedema was evaluated prior to injection, after completion of 3injections and at 6th month follow-up. At the end of third injection the patients ware scheduled for further injections on as needed basis which evaluated by OCT parameters. If the patient is a non-responder or partial responder to Bevacizumab, then a change of AntiVEGF Ranibizumab was offered to the patient. If the patient has non-centre involving macular oedema then focal laser was considered.

\section{Outcome Measurement:}

All the patients examined by one individual (the investigator) in order to minimize the bias. A detailed medical history, clinical examination which includes visual acuity recording, slit-lamp examination of anterior and posterior segment using 90D lens and posterior segment evaluation by indirect ophthalmoscopy using 20D lens. Uncorrected and BCVA using Snellen's visual acuity chart for distant vision and near vision.

IOP recorded using Goldman Applanation Tonometry.

-Pre and post injections BCVA with Snellen's visual acuity chart converted to Log MAR units.

- Pre and post injections central macular thickness measurement using SD-OCT.

-Assessment of ocular \& systemic complication after IVA injection.

Data collection: Data was collected from the patients selected for the study during the period of JULY 2018 to DECEMBER 2019 using the standard case sheet for the study. Complete eye examination was performed such as uncorrected and BCVA, anterior and posterior segment evaluation with slitlamp biomicroscopy using $+90 \mathrm{D}$ lens and posterior segment evaluation by indirect ophthalmoscopy using 20D lens. Pre and post injection BCVA with snellen's visual acuity chart. Pre and post injection retinal thickness measurement using SD-OCT. All patients were examined on post op day 1 of each injection.

The visual acuity evaluated monthly, macular oedema evaluated prior to injection, after completion of 3 injections and at 6 th month followup.

Statistical analysis: Continuous variables are represented as mean and standard deviation where data follows normal distribution, otherwise as median with range. Categorical variables are represented as variables between the groups. Statistical tests such as Fisher exact test, chi square test, $\mathrm{t}$ test, were used accordingly. Correlation was done using spearman's correlation coefficient with $r$ value in the range of -1 to +1 . Association between the variables was considered statistically significant when $p$ value was $<0.05$. Statistical analysis performed using SPSS ver 22.0(SPSS Inc, IL, US).

\section{RESULT}

The mean age of patients was $59 \pm 6.72$ years (4180 years) and mean duration of DM $11.68 \pm 7.2$ years. All the selected patients were treated by 3 injections of Intravitreal bevacizumab with 1-month interval for each injection. The visual acuity was evaluated monthly, macular oedema was evaluated prior to injection, and up to 6 months follow-up. Male to female ratio 2.57:1. Regarding Duration of Diabetes Mellitus, $18 \%$ patients had history of diabetes mellitus for 6 - 10 years, $15 \%$ had a history of diabetes mellitus for 16-20yr, 9\% had 21-25yrs, and $4 \%$ had a $26-30 y r s$. The mean age of diabetes mellitus among study group was $11.68 \pm 7.2$ years. Majority of patients have diabetic retinopathy status of severe NPDR. Ratio between NPDR with PDR 3.8:1. Among study group mild NPDR $1.2 \%$, moderate NPDR $31.7 \%$, severe NPDR $42.7 \%$, and very severe NPDR 3\%, PDR 20.7\%.

Out of 82 eyes in the study group 34(41.5\%) were left eye and 48(58.5\%) were right Eye. 37(62.2\%) have hypertension. 
Table 1. Comparison of residual CMT at the $1^{\text {st }}$ and $6^{\text {th }}$ month after three Bevacizumab injections

\begin{tabular}{|c|c|c|c|}
\hline \multicolumn{3}{|c|}{$\mathrm{CMT} \mu \mathrm{m}$} & \multirow[t]{2}{*}{ P value * } \\
\hline Duration & Mean & SD & \\
\hline Pre-intervention & 436.99 & 135.105 & \\
\hline $1^{\text {st }}$ month & 315.79 & 124.603 & $<0.01$ \\
\hline $6^{\text {th }}$ month & 296.04 & 122.978 & \\
\hline \multicolumn{4}{|c|}{ CMT difference in comparison to Pre-intervention } \\
\hline $\begin{array}{l}\text { Pre-intervention } \\
\text { to } 3^{\text {rd }} \text { month }\end{array}$ & 121.195 & 106.395 & $<0.01$ \\
\hline $\begin{array}{l}\text { Pre-intervention } \\
\text { to } 6^{\text {th }} \text { month }\end{array}$ & 140.951 & 133.174 & \\
\hline
\end{tabular}

*Paired't' test

The table 1 showing the mean CMT was $436.99 \mu \mathrm{m}, 315.79 \mu \mathrm{m}$ and $296.04 \mu \mathrm{m}$ at baseline, $1^{\text {st }}$ month, and $6^{\text {th }}$ month respectively. The mean difference was found to be statistically significant $(p<0.01)$.

Table 1 showing the mean difference of CMT at pre-intervention and post-intervention of $3^{\text {rd }}$ month was $121.19 \mu \mathrm{m}$. The mean difference of CMT at pre-intervention and post-intervention of $6^{\text {th }}$ month is $140.95 \mu \mathrm{m}$. The difference found to be statistically significant.

Table 2. The mean comparison of best corrected visual acuity for distance (BCVA) at Pre intervention and $1^{\text {st }}$ month and 6th month follow-up.

\begin{tabular}{|c|c|c|c|c|c|}
\hline \multirow[t]{2}{*}{ BCVA } & \multicolumn{5}{|c|}{ Number of Eyes } \\
\hline & $\begin{array}{l}\text { Pre } \\
\text { intervention }\end{array}$ & $\begin{array}{l}1^{\text {st }} \text { month after } \\
1^{\text {st }} \text { Injection }\end{array}$ & $\begin{array}{l}1^{\text {st }} \text { month after } \\
2^{\text {nd }} \text { Injection }\end{array}$ & $\begin{array}{l}1^{\text {st }} \text { month after } \\
3^{\text {rd }} \text { injection }\end{array}$ & $\begin{array}{l}\text { 6th month } \\
\text { follow-up }\end{array}$ \\
\hline$\leq 6 / 60$ & 16 & 5 & 3 & 1 & 4 \\
\hline $6 / 36-6 / 24$ & 19 & 23 & 14 & 11 & 8 \\
\hline $6 / 18-6 / 12$ & 47 & 38 & 35 & 24 & 15 \\
\hline$>6 / 12$ & 0 & 16 & 30 & 46 & 55 \\
\hline Total & 82 & 82 & 82 & 82 & 82 \\
\hline P-value\# & 0.02 & & 0.03 & $<0.01$ & $<0.01$ \\
\hline
\end{tabular}

\#Fisher exact test

By using fisher exact test, $\mathrm{P}<0.05$ suggestive of statistically significant difference in BCVA at all follow-ups compared to baseline. 


\section{RESEARCH ARTICLE}

Table 3: The mean comparison of Log MAR units of BCVA at Pre intervention and $1^{\text {st }}$ month and 6th month follow-up.

\begin{tabular}{llll}
\hline & \multicolumn{2}{c}{ BCVA log MAR units (mean \pm SD) } & P value \\
\cline { 2 - 3 } & Pre intervention & $\begin{array}{l}\text { Mean difference of log MAR } \\
\text { units when compared to } \\
\text { pre-intervention }\end{array}$ & \\
\hline Pre-intervention & $0.64 \pm 0.28$ & & $<0.01$ \\
\hline 1 month after 1st Injection & $0.48 \pm 0.27$ & $0.16 \pm 0.08$ & $<0.01$ \\
\hline 1 month after 2nd Injection & $0.36 \pm 0.24$ & $0.28 \pm 0.2$ & $<0.01$ \\
\hline 1 Month after 3rd injection & $0.27 \pm 0.24$ & $0.37 \pm 0.24$ & \\
\hline At 6 ${ }^{\text {th }}$ Month follow-up & $0.23 \pm 0.27$ & $0.41 \pm 0.33$ & \\
\hline
\end{tabular}

Based on paired t test analysis, $p<0.01$, suggestive of statistically significant difference in Log MAR units at all follow-ups compared to baseline (Table 3).

Correlation between CMT and BCVA: Spearman's Correlation analysis between CMT and Log MAR units showed the correlation coefficient of $0.54,0.07$, and 0.75 were seen at Pre intervention, at 3 Months, and at 6 Months respectively with significant difference $(P<0.01)$ (Figure 1).

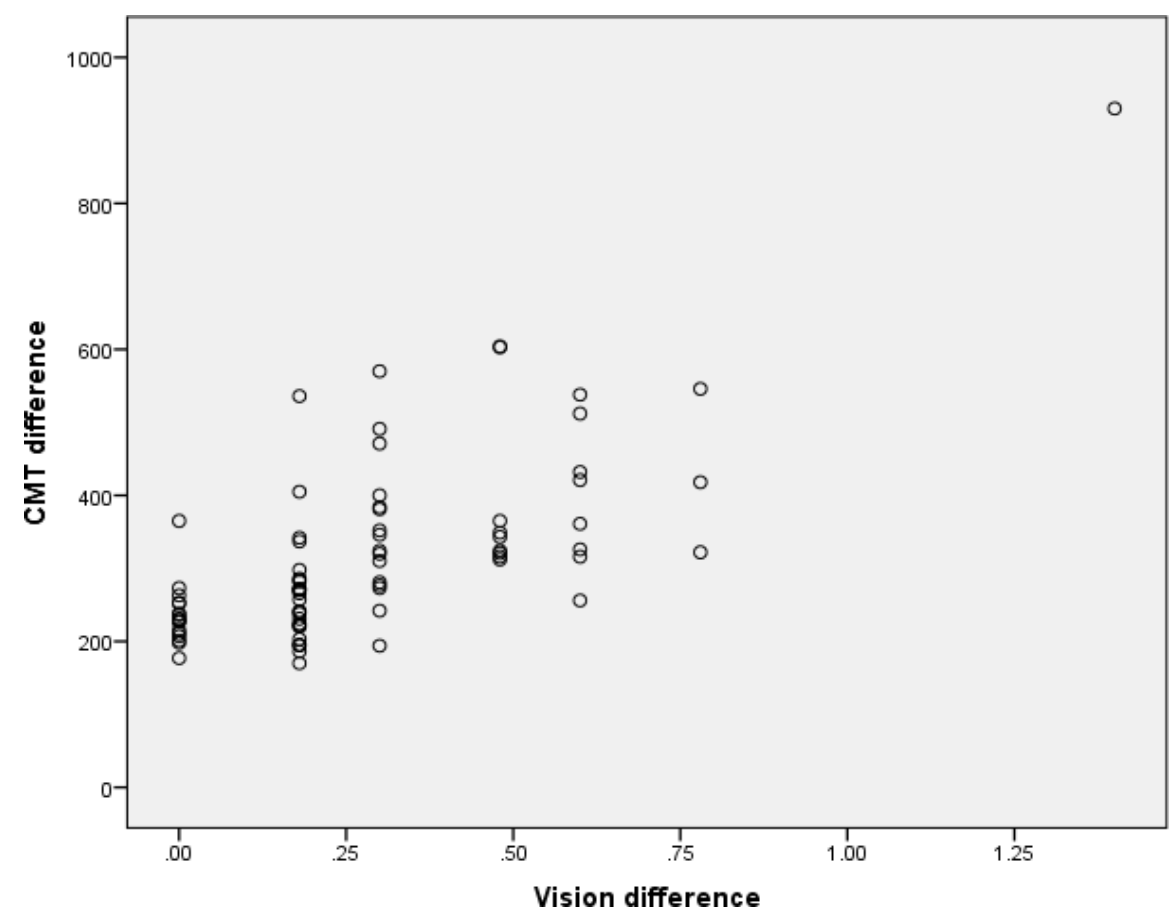

Figure 1. Spearman's Correlation analysis between CMT and Log MAR units at 3 months, and at baseline/3 months difference 


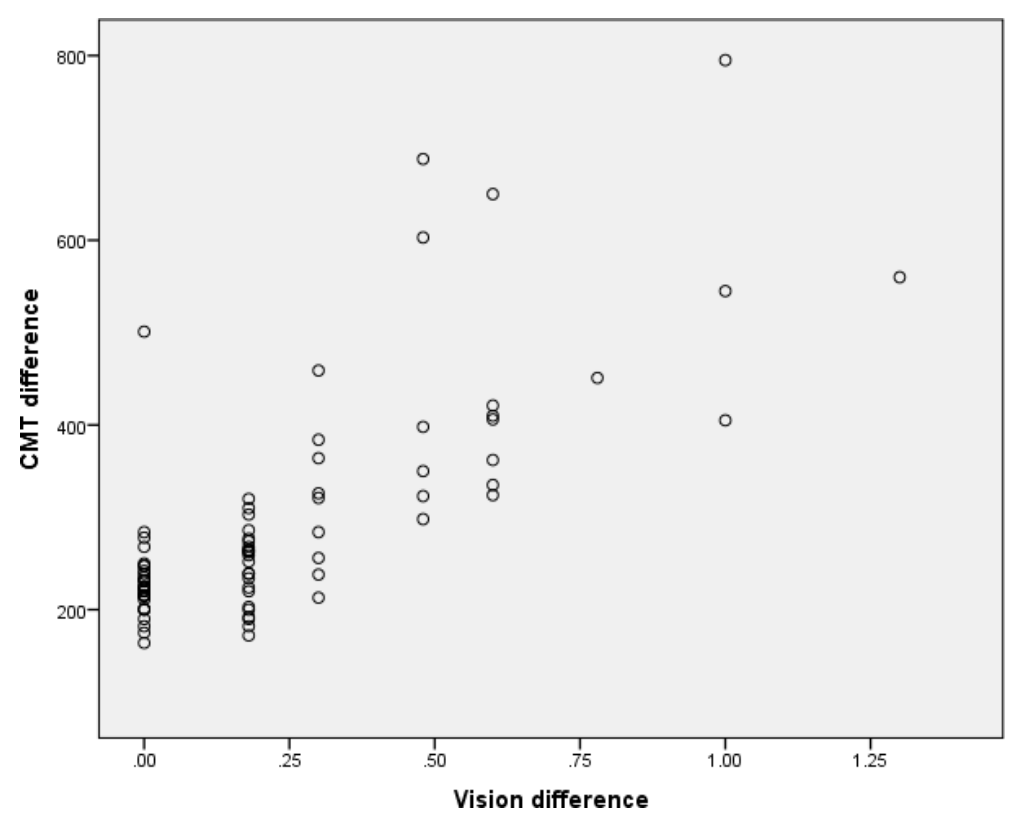

Figure 2. Correlation analysis of CMT and BCVA at 6 months

Correlation of difference in CMT and difference in BCVA when compared to baseline and at 6 months, it shows significant positive correlation between CMT and BCVA (Figure 2).

Table 4. Comparison of BCVA for near vision with preintervention and IOP changes during study follow-up

\begin{tabular}{|c|c|c|c|c|c|}
\hline $\begin{array}{l}\text { BCVA } \\
\text { for Near } \\
\text { Vision }\end{array}$ & $\begin{array}{l}\text { Pre- } \\
\text { intervention } \\
\text { [No. of eyes] }\end{array}$ & $\begin{array}{l}\text { At } 1^{\text {st }} \text { month } \\
\text { after } 1^{\text {st }} \\
\text { Injection[No } \\
\text {. of eyes] }\end{array}$ & $\begin{array}{l}\text { At } 1^{\text {st }} \\
\text { month } \\
\text { after } 2^{\text {nd }} \\
\text { Injection[N } \\
\text { o. of eyes] }\end{array}$ & $\begin{array}{l}\text { At } 1^{\text {st }} \\
\text { Month } \\
\text { after } 3^{\text {rd }} \\
\text { Injection[N } \\
\text { o of eyes] }\end{array}$ & $\begin{array}{l}\text { At } 6^{\text {th }} \\
\text { Month } \\
\text { after } 3^{\text {rd }} \\
\text { Injection[N } \\
\text { o of eyes] }\end{array}$ \\
\hline N12 & 5 & 2 & 1 & 1 & 1 \\
\hline N10 & 17 & 6 & 4 & 3 & 3 \\
\hline N8 & 42 & 47 & 33 & 25 & 17 \\
\hline N6 & 18 & 27 & 44 & 53 & 61 \\
\hline$P$ value\# & \multicolumn{2}{|c|}{$<0.01$} & $<0.01$ & 0.03 & $<0.01$ \\
\hline \multicolumn{6}{|c|}{ IOP changes } \\
\hline Mean \pm SD & $14.26 \pm 1.64$ & $14.91 \pm 2.46$ & $14.56 \pm 2.08$ & $15.2 \pm 2.52$ & $14.63 \pm 2.36$ \\
\hline P value* & \multicolumn{2}{|c|}{0.32} & 0.33 & 0.71 & 0.08 \\
\hline
\end{tabular}

\#Fisher exact test; * Paired't' test

Based on Fisher exact test, $p<0.01$, suggestive of statistically significant difference in BCVA for near at all follow-ups compared to baseline.

Based on paired t-test analysis, it's not statistically significant in IOP changes between Pre intervention and upto $6^{\text {th }}$ month follow up. 
Complications: The Results shows subconjunctival haemorrhage post injection day 1 around $10.9 \%$ - $12.1 \%$ cases and raised intraocular pressure (IOP) post injection day 1 around $2.4 \%-3.6 \%$. Nocomplications at 3rd month and 6th month.

BCVA analysis from baseline: The Results showing $69.5 \%$ cases improved $\geq 2$ Snellen lines at 3 months and $78 \%$ cases improved $\geq 2$ Snellen lines at 6 months.

CMT outcomes at 6th month: There were reduced macular edema se en in $69.5 \%$ cases, persistentmacular edema in $12.1 \%$, refractory macular edema in $7.3 \%$ cases, and recurrence in $10.9 \%$ cases.

Table 5. Central macular thickness (CMT) in recurrence of macular edema(ME) cases at 6 months and Mean BCVA in Recurrent ME cases at 6 months compared with pre intervention and 3 months.

\begin{tabular}{|c|c|c|c|c|c|}
\hline & & Baseline & 3 month & 6 month & $P$ value \\
\hline Persistent macular & CMT & $545.91 \pm 111.97$ & $370.52 \pm 71.43$ & $341.08 \pm 122.75$ & $0.01^{*}$ \\
\hline edema & BCVA & $0.85 \pm 0.28$ & $0.45 \pm 0.20$ & $0.34 \pm 0.23$ & $0.09 *$ \\
\hline Refractory macular & CMT & $482.53 \pm 136.98$ & $497.76 \pm 161.07$ & $407 \pm 169.64$ & $>0.05^{*}$ \\
\hline edema & BCVA & $0.53 \pm 0.24$ & $0.44 \pm 0.31$ & $0.38 \pm 0.30$ & $>0.05^{*}$ \\
\hline \multicolumn{2}{|c|}{$\begin{array}{l}\text { CMT in recurrence } \\
\text { of ME cases at } 6 \text { months }\end{array}$} & $447.66 \pm 91.35$ & $287.33 \pm 53.70$ & $453 \pm 150.19$ & $<0.01^{*}$ \\
\hline \multicolumn{2}{|c|}{$\begin{array}{l}\text { BCVA in } \\
\text { Recurrence of ME cases at } 6 \\
\text { months }\end{array}$} & $0.58 \pm 0.15$ & $0.26 \pm 0.21$ & $0.65 \pm 0.39$ & $<0.01 *$ \\
\hline
\end{tabular}

Table 5 showing CMT in Recurrent macular edema cases at baselinewas $447.66 \pm 91.35$, at 3months decreased to $287.33 \pm 53.70$, and at 6 months again increased to $453 \pm 150.19$. By using paired ttest $p$-value $<0.05$ therefore significant increase in CMT at 6 months. The table showing BCVA in Recurrent macular edema cases atbaseline was $0.58 \pm 0.15$, at 3 months improved to $0.26 \pm 0.21$, at 6 months again decreased to $0.65 \pm 0.39$. By using paired t-test $p$-value $<0.05$ therefore significant decrease in BCVA at 6 months. 


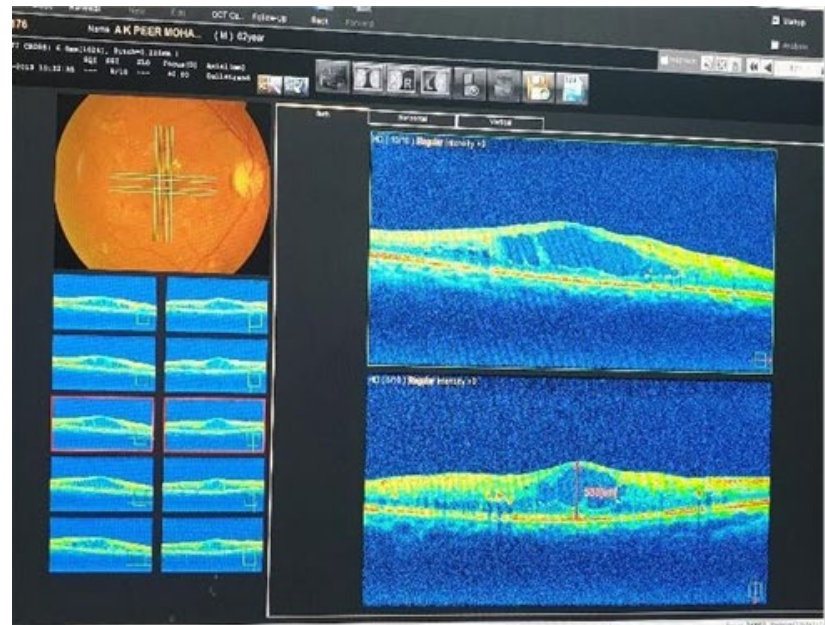

A

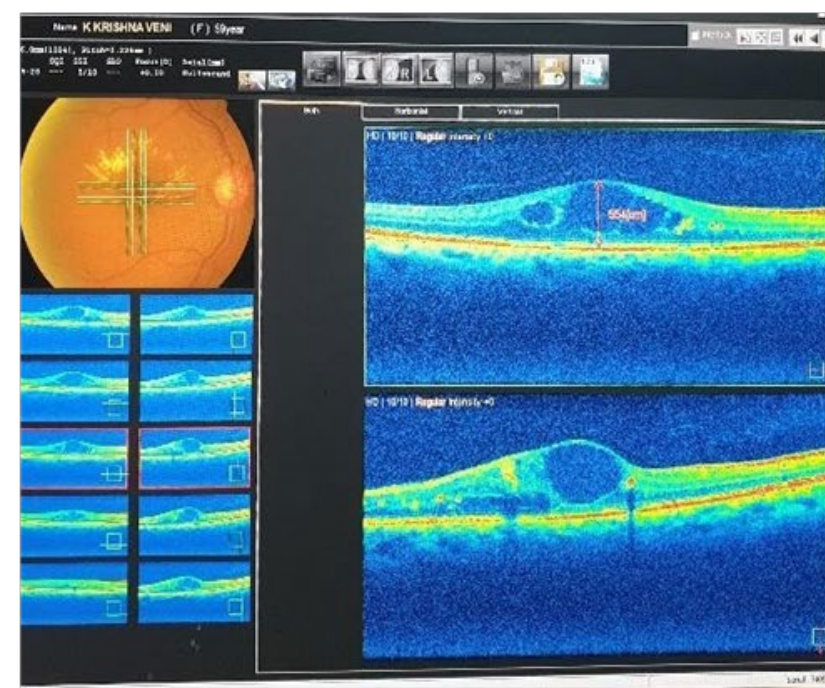

$\mathrm{C}$
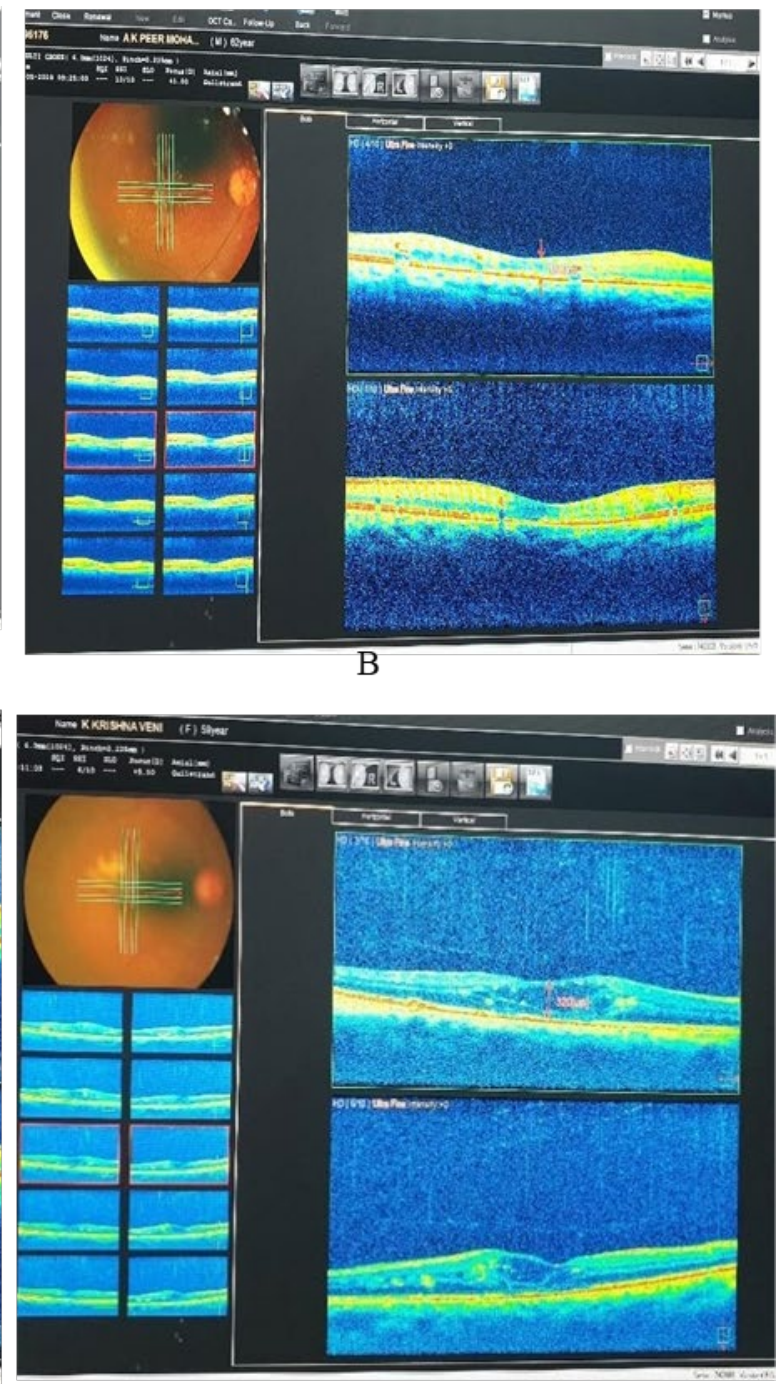

D

Figure 3. Optical Coherence Tomography (OCT) images at pre-intervention and post-intervention of (A \& B), Patient-1, 60 years male and $(C \& D)$, Patient-2 of 59 years female

\section{DISCUSSION}

This prospective interventional non comparative study was undertaken in patients with DME with aim of the safety profile and efficacy of intravitreal bevacizumab. Main objectives of the study are mean resolution of central macular thickness, mean improvement in BCVA and ocular and systemic complications after IVA injections. All the selected patients were treated by 3 monthly injections of IVA followed by as and when required based on OCT findings till follow up of 3 months after $3^{\text {rd }}$ injection. This study was conducted at Sankar foundation eye hospital, Visakhapatnam and included eighty two eyes of sixty eight patients attending OPD from July 2018 to December 2019.All the patients visual acuity evaluated monthly and CMT evaluated prior to injection, 1 month after 3rd injection and at 6th month follow up.

In the present study, the majority belonged to the age group $61-70$ years (46\%) with mean age of of $59 \pm 6.72$ years. This is in concordance with Arevalo et al. ${ }^{25}$ study with mean age of $59.7 \pm 9.3$ years. Males represented $72 \%$ and females represented $28 \%$ of the sample with a male to female ratio $2.57: 1$ in our study. This difference may be because may be more health facilities are availed by men than women. A similar male 
preponderance was documented in Arevalo et al. ${ }^{25}$, and Tareen $\mathrm{IH}$ et al. ${ }^{26}$

Duration of Diabetes ranged between 1-30 years in the sample of patients with Diabetic Macular Edema included in our study. 29\% of patients were having duration of diabetes of 0 5 years, $18 \%$ for $6-10$ years, $25 \%$ for $11-15$ years, $15 \%$ for $16-20$ years, $9 \%$ for $21-25$ years and $4 \%$ for 26-30 years. Mean duration of Diabetes in this study was $11.68 \pm 7.2$ years. It is in concordance with Shyam Vyas and Raba tapa et al, Asim Ateeq et al. which was 11.88 years and $10.15 \pm 3.2$ years respectively. ${ }^{27,28}$

The 82 eyes with Diabetic Macular Edema included in the study were staged for Diabetic Retinopathy according to ETDRS Classification. In the present study eyes showing NPDR were more compared to PDR (79.03\% vs $20.7 \%$ ). More Number of Eyes with NPDR than PDR could be due to early identification of cases with DR due to regular screening and referral of cases from other specialities in the institute. This is in concordance with Sham Vyas et al $(76.92 \%$ vs $23.08 \%)$. This is not in accordance with ozikiris et al. $^{29}$ (40\% vs $\left.60 \%\right)$, Arevalo et al. (43.6\% vs $56.4 \%)$. This may be due to lack of awareness on DR screening among their study population.

In the present study, baseline CMT was $436.99 \pm 135.10 \mu$. This is in concordance with Tareen et al, sham Vyas et al, with mean CMT of $452 \pm 143.1 \mu \mathrm{m}, 463 \pm 173 \mu \mathrm{m}$.

The baseline mean BCVA in this study was $0.64 \pm 0.28$ Log MAR. This is in concordance with Arevalo et al. and Haritoglou et al. ${ }^{30}$ with baseline mean BCVA $0.87 \pm 0.40$ Log MAR and $0.86 \pm 0.38 \log$ MAR units respectively. In Tareen $\mathrm{IH}$ et al. study, the baseline means BCVA $0.42 \pm 0.14 \log$ MAR was better compared to the present study. In Ozkiris $A$ et al. study the baseline mean BCVA1.09 \pm 0.23 log MAR was worse than the present study.
In the present study, the mean CMT changed significantly from $436.99 \pm 135.10 \mu \mathrm{m}$ at baseline to $315.79 \pm 124.60 \mu \mathrm{m}(\mathrm{p}<0.01)$ at 1 month after 3rd IVA and this significant change followed with subsequent follow-up with mean CMT of $296.04 \pm 122.97 \mu \mathrm{m}(\mathrm{p}<0.01)$ at 6 th month. However, the mean change was a bit lower at 6th month when compared to the 1 month after 3rd IVA. The resolution of CMT more during injections period compared with follow-up.

In Arevalo et al. study, the results were very similar to the present study. In this study the mean CMT of $387 \pm 182 \mu \mathrm{m}$ at baseline is decreased to $287 \pm 102 \mu \mathrm{m}, 282 \pm 115 \mu \mathrm{m}$, and $275 \pm 118 \mu \mathrm{m}$ at 1 month, 3 months and 6 months follow up, respectively.

In Tareen IH et al. study the mean CMT of $452.9 \pm 143 \mu \mathrm{m}$ at baseline decreased to $279.8 \pm 65 \mu$ at $3 r d$ month follow up. This study was like the present study in giving 3 consecutive IVB injections each 1 month apart and the results were in concordance

In Haritoglou et al., study, mean central retinal thickness was $501 \pm 163 \mu$ at baseline. Two weeks postoperatively, a significant decrease of mean retinal thickness to $425 \pm 180 \mu \mathrm{m}$ was observed. Six weeks after the injection, mean macular retinal thickness had further decreased to 416 $\pm 180 \mu \mathrm{m}, \quad$ a highly significant difference compared with baseline. After 12 weeks, mean retinal thickness further decreased to $377 \pm 117$ $\mu \mathrm{m}$.

In the present study at baseline, the mean BCVA was $0.64 \pm 0.28$ Log MAR. This improved significantly to $0.48 \pm 0.27(p<0.01)), 0.36 \pm 0.24$ $(p<0.01))$, and $0.27 \pm 0.24(p<0.01), 0.23 \pm 0.27 \mathrm{Log}$ $\operatorname{MAR}(p<0.01))$ at 1 month, 2 months, and 3 months, 6 months respectively, these changes are statistically significant. This finding correlates with the change in CMT with IVA injections. 
The improvement of BCVA is also more with 1st IVA when compared to subsequent IVAs.

In Arevalo et al. by 1 month the mean BCVA improved from 0.87 to 0.6 Log MAR, a difference which was statistically significant. This was maintained throughout 6 months. At 3rd and 6th months follow up the mean BCVA did not differ statistically.

In Tareen IH et al. study the mean BCVA at baseline was $0.42 \pm 0.14 \log$ MAR. At one month after the 1st injection BCVA improved to $0.34 \pm 0.13$ Log MAR unit, with statistical significant difference. This improvement in BCVA was maintained after 2nd and 3rd injections which were $0.25 \pm 0.12 \log$ MAR and $0.17 \pm 0.12$ Log MAR, respectively. These results were in concordance with present study.

In Haritoglou et al. study, at baseline, mean visual acuity was $0.86 \pm 0.38$ Log MAR. After 2 weeks, mean visual acuity had improved to 0.80 \pm 0.37 Log MAR on Snellen charts (not significant). Six weeks after the injection, a significant improvement to $0.75 \pm 0.37 \log$ MAR was observed. Twelve weeks after the injection, some regression of the increase in mean visual acuity to $0.84 \pm 0.41$ Log MAR was noted.

In the present study, we found a positive correlation between reduction in CMT and improvement in BCVA at 1 month after $3^{\text {rd }}$ injection. using Spearman's correlation coefficient, which suggests that as CMT reduces, visual acuity improves. The correlation was weakly positive at 3 months but strongly positive at 6 months. This may be due to multiple factors like macular ischemia, hard exudates, etc. This finding is consistent with a study carried out by Bressler SB et al. ${ }^{31}$ in which results showing positive correlation of improvement in BCVA with reduction in CMT and also a few cases which didn't keep up with these results due to macular ischemia, lipid exudation, etc
In the present study, BCVA for Near vision changed significantly from baseline. Higher baseline CMT may be responsible for poorer near vision.

In the present study, mean IOP values were $14.2 \pm 1.6 \mathrm{~mm} \mathrm{Hg}, 14.9 \pm 2.4 \mathrm{mmhg}, 14.5 \pm 2.08$ mmhg, $15.2 \pm 2.5 \mathrm{~mm} \mathrm{Hg}, 14.6 \pm 2.36 \mathrm{~mm} \mathrm{Hg}$ at baseline, 1 month after 1 st injection, 1 month after 2 nd injection, 1 month after 3rd injection and at 6 th month respectively. No Statistically significant difference was found at any evaluation.

Xiaoyun Fang et al. ${ }^{32}$ mean IOP values were $14.2 \pm 3.1 \mathrm{mmHg}, 13.9 \pm 3.0 \mathrm{mmHg}, 14.4 \pm 3.0$ $\mathrm{mmHg}$ and $14.4 \pm 3.4 \mathrm{mmHg}$ at baseline, and 24 weeks, 8 weeks and 12 weeks post-injection, respectively. No significant difference was found at any evaluation.

The present study shows subconjunctival haemorrhage post injection day 1 around 10.9\% - $12.1 \%$ cases and raised IOP post injection day 1 around $2.4 \%-3.6 \%$.

No other ocular and systemic complications were observed during follow-up. Several reports of ocular haemorrhage following the use of intravitreal anti VEGF drugs. Subconjunctival haemorrhage has been reported to occur in nearly $10 \%$ of injections, with higher frequency in patients who were receiving aspirin. Acute rise of intraocular pressure (IOP) after intravitreal injection is procedure-related and lasts a few hours at most. A study done by Fung et al. ${ }^{33}$ on the international intravitreal bevacizumab safety survey. None of the adverse event rates exceeded $0.21 \%$. intravitreal bevacizumab injections did not show an increased rate of potential drug- related ocular or systemic events. 
In the present study, $69.5 \%$ cases BCVA improved $\geq 2$ Snellen lines at 3 months, 30.5\% cases remained stable. In Tareen $\mathrm{IH}$ et al. study BCVA improved $\geq 1$ ETDRS line in $69.2 \%$ cases at 3 months, 26.9\% cases remained stable, 3.8\% cases decreased $\geq 1$ ETDRS line. In Shyam Vyas et al. study BCVA improved $\geq 2$ ETDRS lines in $42.3 \%$ cases at 3 months, $46.15 \%$ cases remained stable, $11.53 \%$ cases decreased $\geq 2$ ETDRS lines. These results were in concordance in with present study.

In the present study $56 \%$ cases Recovered with 3 injections of intravitreal bevacizumab. $28 \%$ cases persistent macular edema and 15.8\% cases Refractory to treatment. An analysis of the DRCR. net protocol T study revealed that the incidence of persistent DME after 3 consecutive monthly injections was $50.8 \%, 53.2 \%$ and $72.9 \%$ through week 12 , and $31.6 \%, 41.5 \%$ and $65.6 \%$ through week 24 in eyes that received aflibercept, ranibizumab and bevacizumab, respectively. ${ }^{34}$

A study done by Gabriel Katz et al., ${ }^{35} 50 \%$ cases treatment was switched to Ranibizumab after 3 to 6 bevacizumab injections due to persistent macular edema. BOLT study a prospective randomised trial of intravitreal bevacizumab or laser therapy in the management of diabetic macular edema. $21.6 \%$ patients achieved dry macula at 4 months in bevacizumab group. In the present study Out of 82 eyes 36 eyes switched from Bevacizumab to Ranibizumab injections after 3injections of bevacizumab. Out of 36 eyes 23 eyes have persistent macular edema and 13 eyes have refractory macular edema.

In the present study $78 \%$ cases BCVA improved $\geq 2$ snellen lines at 6 months, $20.7 \%$ cases remained stable, $1.2 \%$ cases decreased $\geq 2$ snellen lines. In Tareen IH et al. study BCVA improved $\geq 1$ ETDRS line in $73 \%$ cases at 6 months, $20.5 \%$ cases remained stable, $6.4 \%$ cases decreased $\geq 1$ ETDRS line. In Shyam Vyas et al. study BCVA improved $\geq 2$ ETDRS lines in $42.3 \%$ cases at 6 months, $48.07 \%$ cases remained stable, $9.61 \%$ cases decreased $\geq 2$ ETDRS lines. In Arevalo et al. study BCVA improved $\geq 2$ ETDRS lines in $55.1 \%$ cases at 6 months, $41.1 \%$ cases remained stable, $3.8 \%$ cases decreased $\geq 2$ ETDRS lines. These results were in concordance with present study.

In the present study $69.5 \%$ cases Recovered with 3 injections of intravitreal bevacizumab. $12.1 \%$ cases persistent macular edema and $7.3 \%$ cases Refractory to treatment, $10.9 \%$ cases recurrence of macular edema at 6 th month follow-up. BOLT study a prospective randomized trial of intravitreal bevacizumab or laser therapy in the management of diabetic macular edema. $56.7 \%$ patients classified as non-responders at 24 months due to persistent macular edema in bevacizumab group. ${ }^{34}$

In Aseem Ateeq et al. study, out of the 54 Eyes of 54 Patients who were given the Intravitreal injection of Avastin (Bevacizumab), 43 Eyes (79.6\%) showed $>10 \%$ decrease in macular thickness from pre-injection thickness, 10 Eyes (18.5\%) showed $<10 \%$ decrease and 1 Eye $(1.9 \%)$ showed increase in macular thickness post operatively after one month.

In persistent macular edema cases Mean CMT reduced from $370.52 \pm 71.43 \mu \mathrm{m}$ after the last bevacizumab injection to $341.08 \pm 122.75 \mu \mathrm{m}$ following Ranibizumab injections ( $p \leq 0.01$ ), this was statistically significant. Mean BCVA improved from $0.45 \pm 0.20$ after the last bevacizumab injection to $0.34 \pm 0.23(p=0.09)$, this was not statistically significant. Gabriel katz et $a .^{35}$ study done to evaluate the efficacy of switching from bevacizumab to ranibizumab in patients with diabetic macular edema (DME). The difference in VA between any of these fixed timepoints was not statistically significant. 
The mean CMT was significantly lower after the first 3 ranibizumab injections and at the final follow-up $(p<0.001)$.These results were in concordance with present study.

In Refractory macular edema cases Mean CMT reduced from $497.76 \pm 161.07 \mu \mathrm{m}$ after the last bevacizumab injection to $407.84 \pm 169.64 \mu \mathrm{m}$ following Ranibizumab injections ( $p=0.1$ ), Mean BCVA improved from $0.44 \pm 0.31$ after the last bevacizumab injection to $0.38 \pm 0.30(p=0.6)$. In M Ashraf et al. ${ }^{36}$ study switching to Ranibizumab in Diabetic macular edema refractory to Bevacizumab treatment. 34 eyes switched to ranibizumab showed a statistically significant improvement in mean BCVA from $0.67 \pm 0.39$ log MAR to a mean of $0.55 \pm 0.36 \log \operatorname{MAR}(P<$ 0.05). In addition, there was a statistically significant decrease in central subfield thickness (CST) from a mean of $475.3 \pm 122.8$ to a mean of $417.3 \pm 109.1(P<0.05)$. In the present study Mean CMT, Mean BCVA after switching to Ranibizumab not significant may be due to study done on small no of cases results may vary.

In present study recurrence of macular edema at 6 months in 9 cases. Out of 9 cases 5 cases completely responded with 3 injections becacizumab at the end of 3 months. Remaining 4 cases even with treatment after 3 months they showed increase in macular edema with decreased visual acuity. In Roh et al. ${ }^{37}$ study at 6 weeks after the 1st injection of bevacizumab in Clinically significant DME, BCVA increased significantly, CMT decreased markedly, which returned to Near baseline at 12 weeks. So repeated administration of IVA may lead to improvement in CSME cases.

In xiaoyun Fang et al. study done on bevacizumab in DME concluded that therapeutic effect is temporary and repeat treatment may be needed. Recurrence of macular edema may be due to uncontrolled Diabetes mellitus and other risk factors that leads to progression of Diabetic Retinopathy.

Limitations of this study includes Small sample size included in the present study. The results would have been stronger and power could have been improved if the sample size would have been large. There is no control group in the study as randomization was not possible, so we cannot rule out the possibility that some of the improvement in macular edema might be associated with improvement in systemic health. Control of DM and other risk factors that leads to progression of DME are not assessed in the present study.

\section{CONCLUSION}

There was significant reduction in CMT at 3 months and 6 months of follow-up as compared to baseline. There was significant improvement in BCVA for Distance at follow-up visit as compared to baseline. Reduction in CMT was positively correlated with improvement in vision though not very strongly in our study. Switching to Ranibizumab in persistent diabetic macular edema cases with bevacizumab injections, there was significant reduction of CMT at $6^{\text {th }}$ month followup. Switching to Ranibizumab in diabetic macular edema refractory to bevacizumab, there was no significant reduction of CMT and improvement of BCVA. Intravitreal injection of Bevacizumab is effective in the treatment of Diabetic macular edema but therapeutic effect is temporary and Repeat treatment may be needed. Intravitreal bevacizumab injections did not show an increased rate of potential drug- related ocular or systemic events. It is a safe and economical therapeutic agent. Optical Coherence Tomography is an important tool in monitoring the progression of macular edema. Baseline OCT testing provides a background for post-interventional comparison. This strategy helps the clinician in early detection of macular edema as well as monitoring postinterventional status and need for future treatment. 


\section{REFERENCES}

1. American Diabetes Association. Diagnosis and Classification of Diabetes Mellitus. Diabetes Care. 2009;32(Suppl 1): S62-S67.

2. Debabrata Das, Somedeb Gupta. Diabetic retinopathy in patients of type 2 diabetes mellitus with diabetic nephropathy. International Journal of Scientific Research. 2020:9(1): 2277 - 8179.

3. Pouya saeedi, inga petersohn, paraskevi salpea, et al,Global and regional diabetes prevalence estimates for 2019 and projections for 2030 and 2045:Results from the international diabetes federation diabetes atlas, $9^{\text {th }}$ edition, 2019 sep:157,107843.

4. R.L.Thomas,S.Halim,S.Gurudas, et al, IDF diabetes atlas:A review of studies utilizing retinal photography on the global prevalence of diabetes related retinopathy between 2015 and 2018, 2019 sep :157,107840.

5. Klein $r$, Klein BE, Moss SE, et al., the Wisconsin Epidemiologic Study of Diabetic retinopathy. XV. the long-term incidence of Macular oedema Ophthalmology, Ophthalmology, 1995;102:7-16

6. Yau JW, Rogers SL, Kawasaki R, Lamoureux EL, Kowalski JW, Bek T, et al. Meta-analysis for eye disease (META-EYE) study group. Global prevalence and major risk factors of diabetic retinopathy. Diabetes Care 2012; 35:556-64.

7. Flaxman SR, Bourne RR, Resnikoff S, Ackland P, Braithwaite T, Cicinelli MV, et al. Vision Loss Expert Group of the Global Burden of Disease Study. Global causes of blindness and distance vision impairment 1990-2020: A systematic review and meta-analysis. Lancet Glob Health 2017;5:e1221-34.

8. Raman R, Rani PK, Reddi Rachepalle $S$, Gnanamoorthy P, Uthra S, Kumaramanickavel G, et al. Prevalence of diabetic retinopathy in India: Sankara Nethralaya diabetic retinopathy epidemiology and molecular genetics study report 2. Ophthalmology. 2009; 116:311-8.

9. Progression of retinopathy with intensive versus conventional treatment in the Diabetes Control and Complications Trial. Diabetes Control and Complications Trial Research Group. Ophthalmology. 1995;102(4):647-61.

10. Dr Lubna Ahmad et al. Prevalence of diabetic macular edema in association with severity of diabetic retinopathy. JMSCR Volume 05 Issue 02 February 2017.

11. Photocoagulation for diabetic macular edema. Early treatment diabetic retinopathy study report number 1 . Early treatment diabetic retinopathy study research group. Arch Ophthalmol. 1985; 103:1796-806.

12. Campochiaro PA, Brown DM, Pearson A, Ciulla T, Boyer $D$, et al. Long-term benefit of sustaineddelivery fluocinolone acetonide vitreous inserts for diabetic macular edema. Ophthalmology. 2011 Apr;118(4):626-635.e2.

13. R. W. Beck, A. R. Edwards, L. P. Aiello et al., "Threeyear follow-up of a randomized trial comparing focal/grid photocoagulation and intravitreal triamcinolone for diabetic macular edema," JAMA Ophthalmology. 2009; 127(3):245-251.

14. Martidis A, Duker J, Greenberg P, Rogers A, Puliafito $C$, Reichel E et al. Intravitreal triamcinolone for refractory diabetic macular edema. Ophthalmology. 2002;109(5):920- 7.

15. Elbendary A, Shahin M. Intravitreal Diclofenac Versus Intravitreal Triamcinolone Acetonide in the Treatment of Diabetic Macular Edema. Retina. 2011;31(10):2058-64.

16. Campochiaro PA, Channa R, Berger BB, Heier JS, Brown DM, Fiedler $U$, et al. Treatment of diabetic macular edema with a designed ankyrin repeat protein that binds vascular endothelial growth factor: a phase I/II study. Am J Ophthalmol. 2013;155(4):697-704, 704.e1-2.

17. Nguyen $Q$, Schachar $R$, Nduaka $C$, Sperling M, Basile $A$, Klamerus $K$ et al. Dose- Ranging Evaluation of Intravitreal siRNA PF-04523655 for Diabetic Macular Edema (the DEGAS Study). Investigative Ophthalmology \& Visual Science. 2012;53(12):7666- 74.

18. Cellini M, Balducci N, Strobbe E, Campos EC. Subtenon injection of natural leukocyte interferon $\alpha-2 a$ in diabetic macular edema: a case report. BMC ophthalmology. 2013;13(1):1-4.

19. Ranieri G, Patruno R, Ruggieri E, Montemurro S, Valerio $P$, Ribatti $D$. Vascular endothelial growth factor (VEGF) as a target of bevacizumab in cancer: from the biology to the clinic. Current medicinal chemistry. 2006;13(16):1845-57.

20. Koukourakis G V, Sotiropoulou-Lontou A. Targeted therapy with bevacizumab (Avastin) for metastatic colorectal cancer. Clin Transl Oncol. 2011 Oct;13(10):710-4 
21. Garcia A, Singh H. Bevacizumab and ovarian cancer. Ther Adv Med Oncol. 2013 Mar;5(2):133-41.

22. Stewart MW. Predicted biologic activity of intravitreal bevacizumab. Retina 2007;27:11961200.

23. F. Prager, S. Michels, K. Kriechbaum et al., Intravitreal bevacizumab (Avastin) for macular oedema secondary to retinal vein occlusion: 12month results of a prospective clinical trial. The British Journal of Ophthalmology 2009:93(4);452456.

24. M. Kondo, N. Kondo, Y. Ito et al., Intravitreal injection of bevacizumab for macular edema secondary to branch retinal vein occlusion: results after 12 months and multiple regression analysis. Retina 2009;29(9):1242-1248.

25. Arevalo JF, Fromow-Guerra J, Quiroz-Mercado H, et al. Primary intravitreal bevacizumab (Avastin) for diabetic macular edema: results from the PanAmerican Collaborative Retina Study group at 6month followup. Ophthalmology.2007;114(4):743750.

26. Tareen IU, Rahman A, Mahar PS, Memon MS. Primary effects of intravitreal bevacizumab in patients with diabetic macular edema. PakJ Med Sci. 2013;29(4):1018- 1022.

27. Vyas S, Thapa R, Bajimaya S, Pradhan E, Paudyal G. Anatomical and visual outcome of intravitreal bevacizumab (Avastin) in patients with diabetic macular edema. Nepal J Ophthalmol 2016;8(1):5461.

28. Asim Ateeq, Muhammad Ali Tahir, Alyscia Cheema,Arif Dahri,Saifullah Tareen.Intravitreal injection of bevacizumab in diabetic macular edema. Pak J Med Sci; 2014;30(6):1383-1387.

29. Özkiriş A. Intravitreal bevacizumab (Avastin) for primary treatment of diabetic macular oedema. Eye. 2009;23(3):616-20.

30. Haritoglou C, Kook D, Neubauer A, Wolf A, Priglinger S, Strauss R, Gandorfer A, Ulbig M, Kampik A. Intravitreal bevacizumab (Avastin) therapy for persistent diffuse diabetic macular edema. Retina. 2006;26(9):999-1005.

31. Bressler SB, Qin H, Beck RW, et al. Factors Associated with Changes in Visual Acuity and OCT Thickness at 1 Year after Treatment for Diabetic Macular Edema with Ranibizumab. Archives of ophthalmology.2012;130(9):1153-1161.

32. Fang $X$, Sakaguchi $H$, Gomi F, Oshima $Y$, Sawa $M$, Tsujikawa M, Ikuno Y, Kamei M, Kusaka S, Tano Y. Efficacy and safety of one intravitreal injection of bevacizumab in diabetic macular oedema. Acta ophthalmologica. 2008;86(7):800-5.

33. Fung $A E$, Rosenfeld PJ, Reichel E. The International Intravitreal Bevacizumab Safety Survey: using the internet to assess drug safety worldwide. $\mathrm{Br} J$ Ophthalmol. 2006;90(11):1344-1349.

34. Rajendram Ranjan, Samantha Fraser-Bell, Andrew Kaines et al. A 2-year prospective randomized controlled trial of intravitreal bevacizumab or laser therapy (BOLT) in the management of diabetic macular edema: 24-month data: report 3. Archives of ophthalmology, 2012, 130.8: 972-979.

35. Katz G, Moisseiev E, Goldenberg D, et al. Ranibizumab for persistent diabetic macular edema after bevacizumab treatment. Eur J Ophthalmol. 2017;27(2):210-214.

36. Ashraf M, Souka AA, Varela MD, El Kayal H, Schlottmann PG. Switching to ranibizumab in diabetic macular oedema refractory to bevacizumab treatment. Cambio a ranibizumab en edema macular diabético refractario al tratamiento conbevacizumab. Arch Soc Esp Oftalmol. 2018;93(11):523-529.

37. Roh, Mi In, Byeon, Suk Ho, Kwon, Oh Woong. Repeated Intravitreal Injection Of Bevacizumab For Clinically Significant Diabetic Macular Edema. Retina: 2008;28(9):1314- 1318.

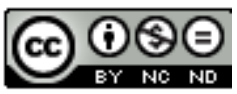

This work licensed under Creative Commons Attribution 